\title{
Properties of IZTO Thin Films Deposited on PET Substrates with The $\mathrm{SiO}_{2}$ Buffer Layer
}

\author{
Jong-Chan Park*, Seong-Jun Kang**, Dong-Hoon Chang***, and Yung-Sup Yoon $* *$ \\ *Department of Electronic Engineering, Inha University, Incheon 402-751, Korea \\ **Department of Electric and Semiconductor Engineering, Cheonnam University, Yeosu 550-749, Korea \\ ***Department of Information \& Communication Engineering, Inha University, Incheon 402-751, Korea
}

(Received November 5, 2014; Revised December 23, December 26, 2014; Accepted December 30, 2014)

\begin{abstract}
150-nm-thick In-Zn-Tin-Oxide (IZTO) films were deposited by RF magnetron sputtering after a 10 to 50 -nm-thick $\mathrm{SiO}_{2}$ buffer layer was deposited by plasma enhanced chemical vapor deposition (PECVD) on polyethylene terephthalate (PET) substrates. The electrical, structural, and optical properties of the $\mathrm{IZTO} / \mathrm{SiO}_{2} / \mathrm{PET}$ films were analyzed with respect to the thickness of the $\mathrm{SiO}_{2}$ buffer layer. The mechanical properties were outstanding at a $\mathrm{SiO}_{2}$ thickness of $50 \mathrm{~nm}$, with a resistivity of $1.45 \times 10^{-3} \Omega$-cm, carrier concentration of $8.84 \times 10^{20} / \mathrm{cm}^{3}$, hall mobility of $4.88 \mathrm{~cm}^{2} / \mathrm{Vs}$, and average IZTO surface roughness of $12.64 \mathrm{~nm}$. Also, the transmittances were higher than $80 \%$, and the structure of the IZTO films were amorphous, regardless of the $\mathrm{SiO}_{2}$ thickness. These results indicate that these films are suitable for use as a transparent conductive oxide for transparency display devices.
\end{abstract}

Key words : IZTO, Sputtering, Transparent conductive oxide, $\mathrm{SiO}_{2}$ buffer layer, Thin film

\section{INTRODUCTION}

F lexible display technology is becoming the next generation of display technology after flat panel display technology. To manufacture these flexible display devices, flexible plastic substrates can be used, such as polyethylene terephthalate (PET), polycarbonate (PC), polyethylene naphthalate (PEN), polyether sulfone (PES). These plastic substrates are light and can be manufactured on a massive scale, which is one of the reasons these plastic substrates are cheaper than recently used glass substrates. However, these plastic substrates have poor physical properties, such as tensile strength and strain, compared to glass substrates. Additionally, their electrical properties and adhesiveness can deteriorate if they are processed at room temperature or high temperature. ${ }^{1,2)}$ Also, plastic substrates absorb humidity and gas, which can deteriorate the device. ${ }^{3,4)}$

New Transparent Conducting Oxide (TCO) materials are being investigated in research to solve the low temperature processing problems of plastic substrates. Presently, due to its high transmittance and conductivity, Indium-Tin-Oxide (ITO) is widely used as a TCO in flat panel display devices such as Organic Light Emitting Diodes (OLEDs), Light Emitting Diodes (LEDs), and Liquid Crystal Displays (LCDs) ${ }^{5-7)}$ However, because ITO has poor surface roughness and low work function, and has to be processed at high

${ }^{\dagger}$ Corresponding author : Yung-Sup Yoon

E-mail : ysyoon@inha.ac.kr

Tel : +82-32-860-7437 Fax : +82-32-868-3654 temperature for fine deposition, there are limits in applying it to flexible display devices.

To solve these problems, amorphous ITO and amorphous In-Zn-Oxide (IZO) can be used. But amorphous ITO has insufficient electrical and optical properties. Amorphous IZO does have acceptable electrical and optical properties, but the process of making sintered IZO targets is complex, so the targets are too expensive to manufacture. ${ }^{1)}$

Zinc-doped ITO (IZTO, Indium-Zinc-Tin-Oxide) has been investigated to solve these problems. Fine electrical and optical properties can be expected using room temperature processing with IZTO. Because IZTO has a high work function, high electric conductivity, and high transmittance, and it can be deposited at room temperature, it is eligible for use in flexible display devices. If IZTO is used as a TCO, it needs no annealing or cooling process, because low temperature processing is possible. ${ }^{8,9)}$

However, IZTO cannot prevent the permeation of humidity and gas from plastic substrates. To prevent this, a buffer layer with a high work function and low reactivity with oxygen must be deposited between the TCO and the substrate. This buffer layer acts as a barrier that prevents the permeation of impurities, makes the surface smooth, and improves the adhesiveness and electrical properties. ${ }^{3,4)}$

To apply IZTO as a TCO, electron beam deposition, plasma enhanced chemical vapor deposition (PECVD), and a variety of sputtering methods have been researched, considering working pressure, reactive gas density, working temperature, and TCO thickness. The conditions that produce the best properties, such as optimum surface roughness, electrical conductivity, and optical transmittance, 
have already been investigated with different deposition methods. However, the materials deposited as a buffer layer and the changes in device characteristics with different thicknesses have not been thoroughly investigated. Therefore, this study investigated the thickness of the buffer layer that produces the best properties by analyzing the differences in the structural, electrical, and optical properties of the IZTO film. The films were deposited by RF magnetron sputtering after depositing $\mathrm{SiO}_{2}$ as a buffer layer on PET film by PECVD. Various thicknesses in the range of 10 to 50 nm were deposited.$^{10,11)}$

\section{Experimental Procedure}

Plastic substrates were cleaned with alcohol and de-ionized water for about 2 to 3 minutes. IZTO $\left(\operatorname{In}_{2} \mathrm{O}_{3} 90 \mathrm{wt} \%\right.$; $\left.\mathrm{ZnO} 5 \mathrm{wt} \% ; \mathrm{SnO}_{2} 5 \mathrm{wt} \%\right)$ thin films were deposited on wellcleaned 1-inch by 1-inch sized PET substrates (125-um, SKC, SH40) by RF magnetron sputtering at room temperature.

As described in Table 1, the RF magnetron sputtering process conditions were as follows: the base vacuum was $4.5 \times 10^{-6} \mathrm{~Pa}$, the active gas (Ar) density was $20 \mathrm{sccm}$, the working pressure was 3 mTorr, and the working temperature was room temperature. IZTO films were deposited with 150 to $160-\mathrm{nm}$ thickness, $50 \mathrm{~W}$ of RF power, and a deposition time of 10 minutes.

Before depositing the IZTO films, $\mathrm{SiO}_{2}$ buffer layers were deposited by PECVD with 10 to 50 -nm thickness under the process conditions in Table 2 . The crystal structures of the IZTO films deposited on the $\mathrm{SiO}_{2}$ buffer layer were analyzed by X-ray diffraction (XRD, XPERT-PRO) from $2 \theta=20^{\circ}$ to $60^{\circ}$ at $40 \mathrm{kV}$ and $30 \mathrm{~mA}$. The surface morphology of the IZTO films deposited on the $\mathrm{SiO}_{2}$ buffer layer were analyzed by AFM (Atomic Force Microscopy), the electrical properties were analyzed by Hall measurements (HMS-3000, Ecopia), and the optical transmittance was analyzed in the wave-

Table 1. Process Conditions of the RF Magnetron Sputtering

\begin{tabular}{cc}
\hline Base pressure & $4.5 \times 10^{-6} \mathrm{~Pa}$ \\
\hline Active gas(Ar) density & $20 \mathrm{sccm}$ \\
Working pressure & $3 \mathrm{mTorr}$ \\
Working temperature & Room temperature \\
RF power & $50 \mathrm{~W}$ \\
Deposited time & $10 \mathrm{~min}$. \\
Deposited IZTO thickness & $150 \sim 160 \mathrm{~nm}$ \\
\hline
\end{tabular}

Table 2. Process Conditions of PECVD

\begin{tabular}{cc}
\hline Working pressure & $800 \mathrm{mTorr}$ \\
\hline Working temperature & Room temperature \\
$\mathrm{RF}$ power & $40 \mathrm{~W}$ \\
$\mathrm{~N}$ density & $20 \mathrm{sccm}$ \\
$\mathrm{N}_{2} \mathrm{O}$ density & $200 \mathrm{sccm}$ \\
$\mathrm{SiH}_{4}$ density & $600 \mathrm{sccm}$ \\
\hline
\end{tabular}

length range of 300 to $800 \mathrm{~nm}$. Based on the results, the figures of merit for the transparent display devices were calculated.

\section{Results and Discussion}

Figure 1 presents the X-ray diffraction pattern of the IZTO/SiO $/ 2$ PET films with various thicknesses of $\mathrm{SiO}_{2}$ buffer layer. Except for the intensive peak at $2 \theta=25.9^{\circ}$, the pattern generally indicates amorphous structure. The intensive peak at $2 \theta=25.9^{\circ}$ agrees with the peak of the PET substrates presented by other researchers. ${ }^{12)}$

Figure 2 presents the surface morphology from AFM images and the average surface roughness of the $\mathrm{IZTO} / \mathrm{SiO}_{2} /$ PET films with various thicknesses of the $\mathrm{SiO}_{2}$ buffer layer. The plastic substrate absorbs humidity and gas. In the deposition process, if the humidity and gas permeate into the deposited layer, pin holes are generated, which could lead to porous thin films. In these porous thin films, the next layer would be deposited first into these porous regions, and the surface morphology would consequently be deteriorated. ${ }^{12)}$ Fig. 2(b) shows a deteriorated surface due to above mentioned plastic problem and the relaxation of stress induced to the substrate. This porous thin film couldn't be used as a TCO.

The $\mathrm{SiO}_{2}$ thin film acts as a buffer layer that can prevent permeation of humidity and gases from the plastic substrates. With increasing thickness of the $\mathrm{SiO}_{2}$ buffer layer $(\leq 30 \mathrm{~nm})$, due to stress relaxation of the substrates, the IZTO thin film is deposited with some disorder, and the surface roughness is also increased. In the region where the thickness of the $\mathrm{SiO}_{2}$ buffer layer is thicker than $30 \mathrm{~nm}$, the $\mathrm{SiO}_{2}$ buffer layer properly acts as a buffer layer, and the surface roughness is decreased. On this smooth surface, there would be an increased deposition rate for the next deposition process, and this means higher adhesiveness.

Figure 3(a) presents the resistivity and sheet resistance of IZTO thin films deposited on $\mathrm{SiO}_{2} / \mathrm{PET}$ films with different

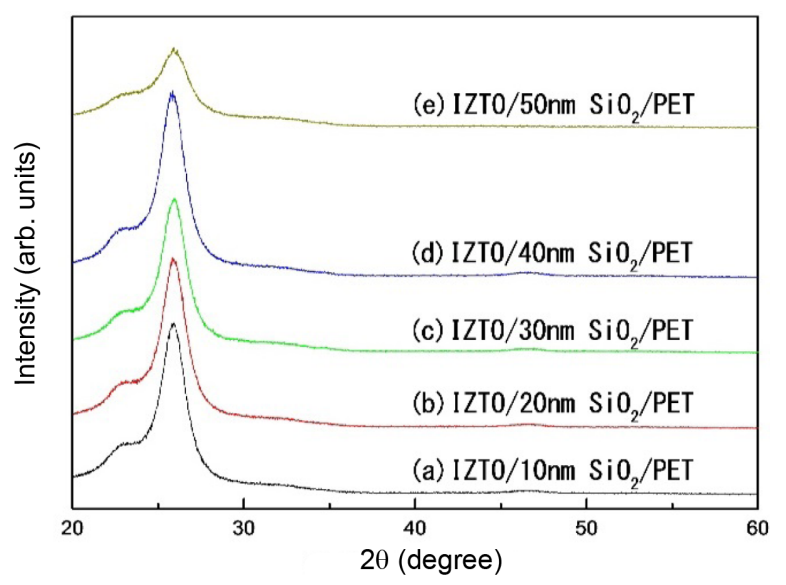

Fig. 1. X-ray diffraction pattern with various thicknesses of the $\mathrm{SiO}_{2}$ buffer layer. 
(a) Bare PET

$\mathrm{Ra}=27.22 \mathrm{~nm}$

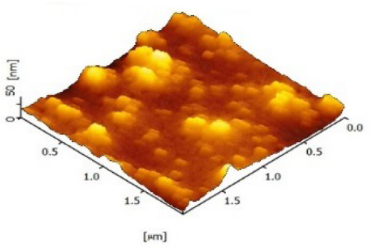

(a) IZTO $10 \mathrm{~nm} \mathrm{SiO} /$ PET $\mathrm{Ra}=12.37 \mathrm{~nm}$

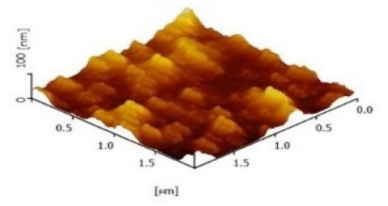

(e) IZTO/30 nm SiO $/ P E T$ $\mathrm{Ra}=14.41 \mathrm{~nm}$

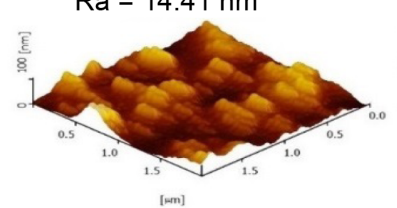

(g) IZTO/50 nm SiO $/$ PET $\mathrm{Ra}=12.64 \mathrm{~nm}$

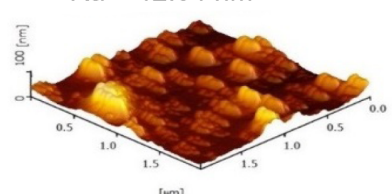

$[\mathrm{mm}]$ (b) IZTO/PET

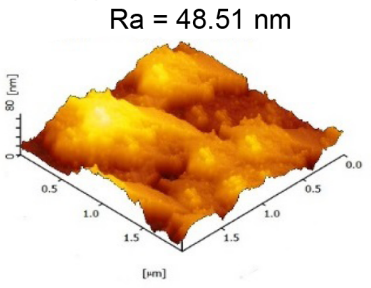

(d) IZTO/20 nm SiO $/$ PET $\mathrm{Ra}=13.77 \mathrm{~nm}$

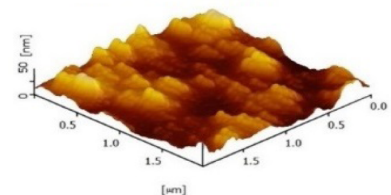

(f) IZTO/40 nm SiO $/$ PET $\mathrm{Ra}=14.34 \mathrm{~nm}$

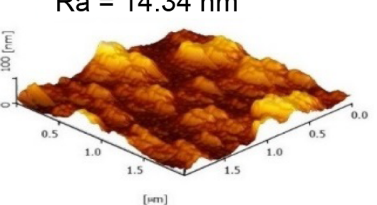

$[\mathrm{man}]$
Fig. 2. AFM images and average roughness of $\mathrm{IZTO} / \mathrm{SiO}_{2} /$ PET films with various thicknesses of the $\mathrm{SiO}_{2}$ buffer layer.

thicknesses of the $\mathrm{SiO}_{2}$ buffer layer. By increasing the thickness of the $\mathrm{SiO}_{2}$ buffer layer $(\leq 40 \mathrm{~nm})$, the resistivity of the IZTO films decreased from $1.95 \times 10^{-3} \Omega$-cm to $1.43 \times 10^{-3} \Omega$ $\mathrm{cm}$ due to increased carrier concentration and smoother surface, and the sheet resistance of the IZTO film is at its lowest, $95.3 \Omega$ /sq, with $40 \mathrm{~nm}$ of $\mathrm{SiO}_{2}$ buffer layer.

Figure 3(b) presents the carrier concentration of IZTO thin films with different thicknesses of the $\mathrm{SiO}_{2}$ buffer layer. The substitution process between $\mathrm{Sn}$ atoms and $\mathrm{Zn}$ atoms makes a carrier. This process occurs at a sharp point. With increasing thickness of the $\mathrm{SiO}_{2}$ buffer layer $(\leq 40 \mathrm{~nm})$, the sharp points in the IZTO surface are increased, thus carrier concentration increased from $5.91 \times 10^{20} / \mathrm{cm}^{3}$ to $9.03 \times 10^{20}$, $\mathrm{cm}^{3}$; the 40-nm-thick buffer layer had the highest carrier concentration. The results were almost the same with the trend of surface roughness.

Figure 3(c) presents the hall mobility of the $\mathrm{IZTO} / \mathrm{SiO}_{2} /$ PET with different thicknesses of the $\mathrm{SiO}_{2}$ buffer layer. With increasing thickness of the $\mathrm{SiO}_{2}$ buffer layer, the Hall mobility was reduced from $5.41 \mathrm{~cm}^{2} / \mathrm{V}$-s to $4.84 \mathrm{~cm}^{2} / \mathrm{V}$-s, and there was no prominent variation.

The $\mathrm{SiO}_{2}$ buffer layer carried out its role well, preventing the permeation of humidity and gas. This buffer layer
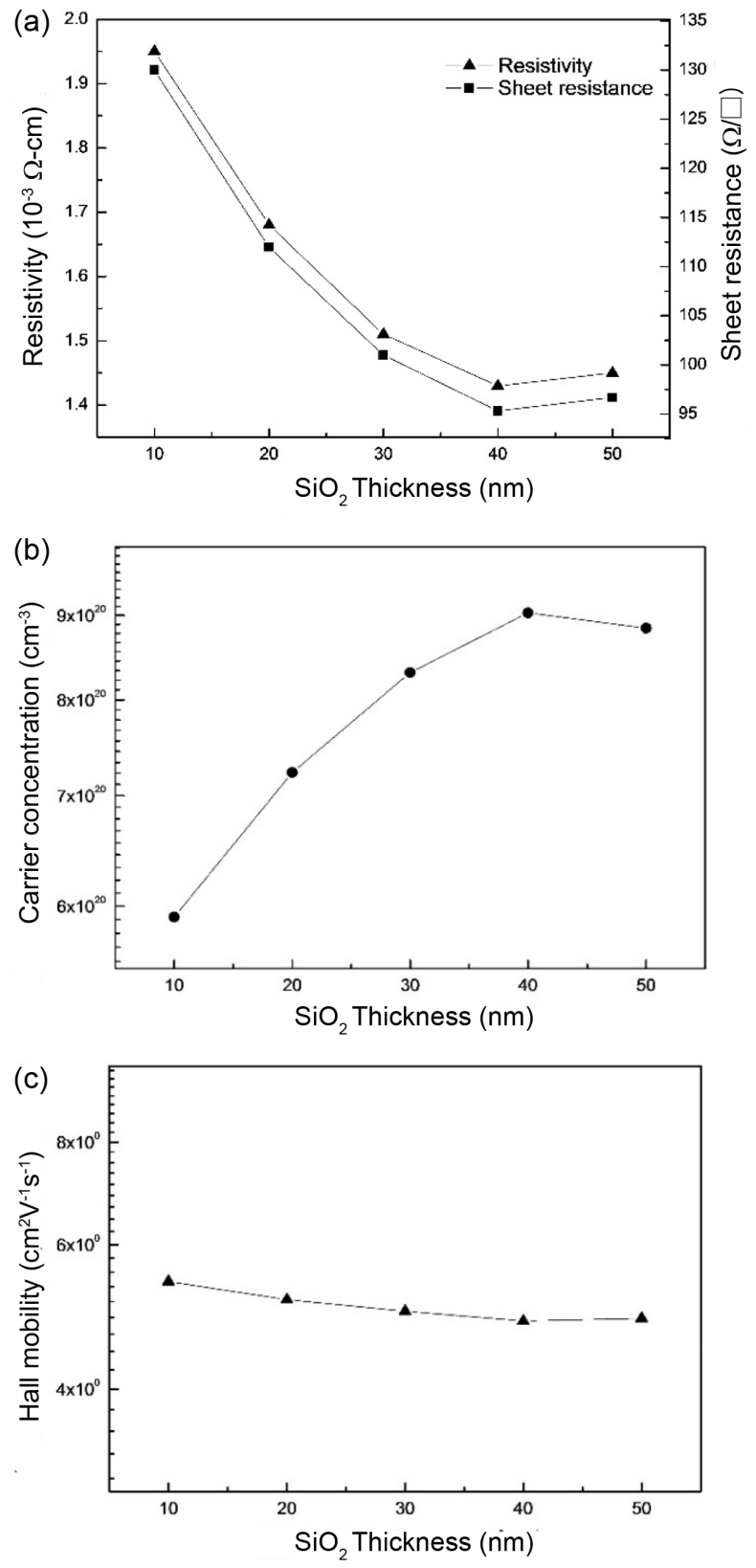

Fig. 3. (a) Resistivity and sheet resistance, (b) Carrier concentration, and (c) Hall mobility of IZTO thin film with various thicknesses of the $\mathrm{SiO}_{2}$ buffer layer.

improved the quality of the IZTO film by making the film's surface smooth, increasing carrier concentration, and reducing resistivity.

Figure 4 presents the optical transmittance of the IZTO/ $\mathrm{SiO}_{2} / \mathrm{PET}$ films after depositing the $\mathrm{SiO}_{2}$ buffer layer at thicknesses of $10 \mathrm{~nm}$ to $50 \mathrm{~nm}$ on the PET substrates with the IZTO compound semiconductor on top. The transmittance was analyzed at different wavelengths in the range of $300 \mathrm{~nm}$ to $800 \mathrm{~nm}$. After depositing the $\mathrm{SiO}_{2}$ buffer layer and the IZTO film, these $\mathrm{IZTO} / \mathrm{SiO}_{2} / \mathrm{PET}$ films exhibited high transmittance, of $80.5 \%$ to $81 \%$, making them suitable 


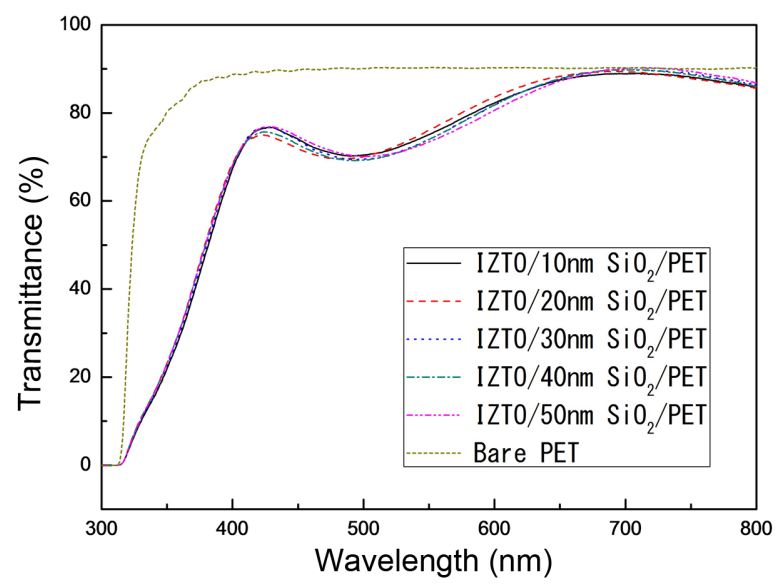

Fig. 4. Transmittance of $\mathrm{IZTO} / \mathrm{SiO}_{2} / \mathrm{PET}$ films with various thicknesses of the $\mathrm{SiO}_{2}$ buffer layer.

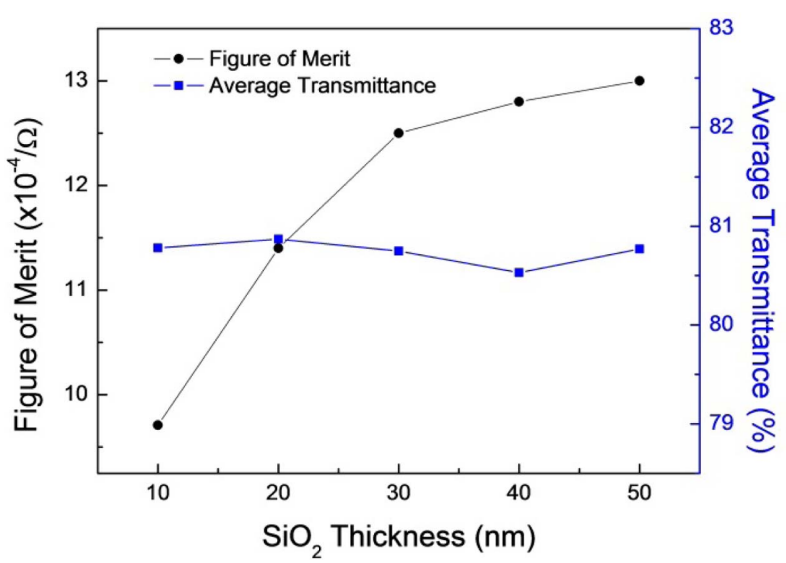

Fig. 5. Average transmittance and figure of merit $(\varphi \mathrm{TC})$ of $\mathrm{IZTO} / \mathrm{SiO}_{2} / \mathrm{PET}$ films with various thicknesses of the $\mathrm{SiO}_{2}$ buffer layer.

for use as the TCO in transparent display devices. With increasing $\mathrm{SiO}_{2}$ buffer layer thickness, the graph shape of the transmittance was almost the same. This means the $\mathrm{SiO}_{2}$ buffer layer thickness had only a small effect on the transmittance. ${ }^{13)}$

Figure 5 presents the figure of merit $\left(\varphi_{\mathrm{TC}}\right)$ and average transmittance in the visible region (400 to $800 \mathrm{~nm}$ ) of IZTO/ $\mathrm{SiO}_{2} / \mathrm{PET}$ films with different thicknesses of the $\mathrm{SiO}_{2}$ buffer layer. The figure of merit for transparent conductive oxide, $\varphi_{\mathrm{TC}}$, which was introduced by Haacke, is defined by $\varphi_{\mathrm{TC}}=\mathrm{T}^{10} / \mathrm{R}_{\text {sheet}}$, where $\mathrm{T}$ is the average transmittance in the visible region, and $R_{\text {sheet }}$ is the sheet resistance analyzed in Fig. 3(a). ${ }^{14)}$ In the case of the $\mathrm{SiO}_{2}$ buffer layer thickness of $50 \mathrm{~nm}$, the figure of merit, $\varphi_{\mathrm{TC}}$, had the highest value of $1.22 \times 10^{-3} / \Omega$.

\section{Conclusion}

This paper analyzed the structural, morphological, electrical, and optical properties of IZTO thin films deposited on PET substrates with various thickness of $\mathrm{SiO}_{2}$ buffer layer.
When fabricated with a $40 \mathrm{~nm}$ thick $\mathrm{SiO}_{2}$ buffer layer the device exhibited the best electrical properties: carrier concentration was $9.03 \times 10^{20} / \mathrm{cm}^{3}$, sheet resistance was $95.3 \Omega$ / sq. And, with a $50 \mathrm{~nm}$ thick $\mathrm{SiO}_{2}$ buffer layer the device had slightly decreased properties: carrier concentration was $8.84 \times 10^{20} / \mathrm{cm}^{3}$, sheet resistance was $96.7 \Omega /$ sq. Hall mobility was almost the same at all $\mathrm{SiO}_{2}$ buffer layer thicknesses.

However, optical transmittance must be considered for transparent devices. Considering the optical transmittance, the figure of merit was $1.20 \times 10^{-3} / \Omega$ for the $40 \mathrm{~nm}$ thick $\mathrm{SiO}_{2}$ buffer layer, while the figure of merit was $1.22 \times 10^{-3} / \Omega$ in the case of the $50 \mathrm{~nm} \mathrm{SiO}_{2}$ buffer layer, due to its slightly higher optical transmittance. The $50 \mathrm{~nm} \mathrm{SiO}_{2}$ buffer layer thickness was demonstrated to be the best case for transparent devices according to the figure of merit.

\section{Acknowledgments}

This work was supported by INHA UNIVERSITY Research Grant.

\section{REFERENCES}

1. N. Ito, Y. Sato, P. K. Song, A. Kaijio, K. Inoue, and Y. Shigesato, "Electrical and Optical Properties of Amorphous Indium Zinc Oxide Films," Thin Solid Films, 496 [1] 99-103 (2005).

2. K. H. Lee and H. W. Jang, "Mechanism for The Increase of Indium-Tin-Oxide Work Function by $\mathrm{O}_{2}$ Inductively Coupled Plasma Treatment," J. Appl. Phys., 95 586-90 (2004).

3. H. Zhuang, J. Yan, C. Xu, and D. Meng, "Transparent Conductive $\mathrm{Ga}_{2} \mathrm{O}_{3} / \mathrm{Cu} / \mathrm{ITO}$ Multilayer Films Prepared on Flexible Substrates at Room Temperature," Appl. Surf. Sci., 307 241-45 (2014).

4. B. Houng, S. L. Lin, S. W. Chen, and A. Wang, "Influence of An $\mathrm{In}_{2} \mathrm{O}_{3}$ Buffer Layer on The Properties of ITO Thin Films," Ceram. Int., 37 [8] 3397-403 (2011).

5. J. H. Kim, K. A. Jeon, G. H. Kim, and S. Y. Lee, "Electrical, Structural, and Optical Properties of ITO Tin Films Prepared at Room Temperature by Pulsed Laser Deposition," Appl. Surf. Sci., 252 [13] 4834-32 (2005).

6. D. Y. Lee, J. R. Lee, G. H. Lee, and P. K. Song, "Study on In-Zn-Sn-O and In-Sn-Zn-O Films Deposited on PET Substrate by Magnetron Co-sputtering System," Surf. Coat. Technol., 202 [22-23] 5718-23 (2008).

7. C. Jang, K. Kim, and K. C. Choi, "Flexible Photoluminescent Display Fabricated With Low-Temperature Process Using PET Substrates," J. Display Technol., 8 [5] 250-55 (2012).

8. T. Ishida, H. Kobayashi, and Y. Nakato, "Structures and Properties of Electron Beam Vaporated Indium Tin Oxide Films as Studied by Xray Photoelectron Spectroscopy and Work Function Measurements," J. Appl. Phys., 73 4344-50 (1993).

9. Y. R. Denny, S. Y. Lee, K. I. Lee, S. J. Seo, S. K. Oh, H. J. Kang, S. Heo, J. G. Chung, J. C. Lee, and S. Tougaard, "Effects of Gas Environment on Electronic and Optical Properties of Amorphous Indium Zinc Tin Oxide Thin 
Films," J. Vac. Sci. Technol. A., 31 031508-1-7 (2013).

10. B. J. Woo, J. S. Hong, S. T. Kim, S. H. Park, and J. J. Kim, "Effect of $\mathrm{A} \mathrm{SiO}_{2}$ Buffer Layer on the Characteristics of $\mathrm{In}_{2} \mathrm{O}_{3}-\mathrm{ZnO}-\mathrm{SnO}_{2}$ Films Deposited on PET Substrates," $J$. Korean Phys. Soc., 48 [6] 1579-82 (2006).

11. X. Ding, J. Yan, T. Li, and L. Zhang, "Transparent Conductive ITO/Cu/ITO Films Prepared on Flexible Substrates at Room Temperature," Appl. Surf. Sci., 258 [7] 3082-85 (2011).

12. C. M. Lee, A. Park, Y. J. Cho, M. W. Park, W. I. Lee, and H.
W. Kim, "Influence of ZnO Buffer Layer Thickness on The Electrical and Optical Properties of Indium Zinc Oxide Thin Films Deposited on PET Substrates," Ceram. Int., 34 [4] 1093-96 (2007).

13. X. Ding, J. Yan, T. Li, and L. Zhang, "Effect of $\mathrm{SiO}_{2}$ Buffer Layer Thickness on The Properties of ITO/Cu/ITO Multilayer Films Deposited on Polyethylene Terephthalate Substrates," Vacuum, 86 [4] 443-47 (2011).

14. G. Haacke, "Transparent Conducting Coatings," Ann. Rev. Mater. Sci., 7 73-93 (1977). 